\title{
The Development of Trade Fair Ecologies in China: \\ Case Studies from Chengdu and Shanghai
}

\author{
Harald Bathelt \& Gang Zeng
}

\author{
Version Post-print/accepted manuscript \\ Citation Bathelt, H., \& Zeng, G. (2014). The development of trade fair ecologies \\ (published version) in China: Case studies from Chengdu and Shanghai. Environment and \\ Planning A, 46(3), 511-530. \\ Copyright / License \\ Publisher's Statement The version of record [Bathelt, H., \& Zeng, G. (2014). The \\ development of trade fair ecologies in China: Case studies from \\ Chengdu and Shanghai. Environment and Planning A, 46(3), 511-530.] is \\ available online at: \\ http://epn.sagepub.com/content/46/3/511 \\ [doi: 10.1068/a45661]
}

Always cite the published version, so the author(s) will receive recognition through services that track citation counts, e.g. Scopus. If you need to cite the page number of the TSpace version (original manuscript or accepted manuscript) because you cannot access the published version, then cite the TSpace version in addition to the published version using the permanent URI (handle) found on the record page. 


\title{
The Development of Trade Fair Ecologies in China: Case Studies from Chengdu and Shanghai
}

\begin{abstract}
Despite China's rapid economic growth, not much is known about the primary places where buyers and sellers from China and abroad meet, make business and circulate information and knowledge, i.e. the national and international trade fairs in the country. Previous reports suggest that the number and size of such events in China is growing and that the trade fair business is in the process of formation. Under these circumstances, we might expect that trade fairs are primarily organized as import or export fairs where buyers and sellers engage in market transactions. Using literature on the role of trade fairs as temporary clusters as a starting point, this paper aims to analyze which interaction and communication patterns can be identified at Chinese trade fairs and whether these events are characterized by similar characteristics as those in highly-industrialized economies. We hypothesize that the trade fair business changes quickly and merges towards structures similar to those in Europe and North America. To investigate this, an explorative study of three national/international trade fairs in Shanghai and Chengdu was designed, involving a total of 102 semi-structured interviews.
\end{abstract}

Keywords: Trade fairs; trade fair ecologies; development; China

JEL Classifications: D83, F59 


\section{Introduction}

Studies of China's economic development over the past decade have provided an abundance of evidence about the rapid expansion of global value chains, foreign direct investments, research and development expenditures and associated regional growth dynamics, especially in high-technology industries such as electronics, telecommunications and other information technology industries (e.g. Fan 2006; Sun and Wen 2007; Wang and Lee 2007; Wang et al. 2010; Wei et al. 2012). Despite rich evidence about the importance of interaction between domestic and international firms (Yeung 2009), little is known about the primary places where buyers and sellers from China and abroad meet, make business and circulate information and knowledge: i.e. the large national and international trade fairs that take place in the country.

While there is a growing knowledge base about the development, characteristics and economic geography of trade fairs in Europe and North America (Allix 1922; Zelinsky 1994; CERMES 2005; Rinallo and Golfetto 2011; Bathelt and Spigel 2012), little is known about trade fair ecologies in China. Although it is generally difficult to obtain reliable trade fair statistics, this appears to be specifically difficult in the context of Asian economies where trade fairs do not have a long tradition and where the trade fair business is in the process of formation. As opposed to many other countries, the trade fair business in China has been under substantial state control/influence through the Ministry of Commerce and the China Council for the Promotion of International Trade. According to AUMA (2008), this has led to lack of transparency with respect to the number and nature of trade fairs and exhibitions in China.

From the limited research that exists, we know that trade fairs in China began to develop in the mid and late 1970s, supported through the opening policy of the country. Initially, this development was state-directed (Schellkes 2003). Prior to China's opening policy, the 
establishment of trade fairs in China was politically driven with the goal to present the country favorably and stimulate trade (Kay 2005). In this time period, relatively small trade fair centers with about 10,000 square meters of indoor exhibition space were established according to Russian conceptions and architecture. Such centers were established in Shanghai and Beijing, as well as in many other large Chinese cities. Already in 1956, Guangzhou became the location of the famous Canton Fair - or Export Commodities Trade Fair (today: China Import and Export Fair). With the opening policy in the 1980s under Deng Xiaoping, the Chinese trade fair business began to expand. Many trade fairs were organized jointly with trade fair organizers from Hong Kong or the United States, while larger ones were still under government control. In this period, the number of foreign firms participating in these events grew rapidly. They attended trade fairs primarily to market their products in the Chinese market. It was not until Jiang Zemin's policies in the early 1990s, however, that new trade fair and convention centers were systematically built at a large scale. At that point, trade fair centers were largely directed to and located within the Coastal Special Economic Zones that had been established. In this period, Shanghai became an important center of trade fair activity in China (Kay 2005).

While Hong Kong and relatively close-by Guangzhou were initially the dominating trade fair places with a gateway function to connect foreign traders to Chinese producers (Powell 2007; Xin and Weber 2008), fair activities in other cities such as Shanghai and Beijing soon picked up. As of today, more than half of all trade fairs are organized by industry associations, another quarter by the state, and the remainder through joint ventures with foreign organizers (Jin et al. 2010b). Despite this, state influence appears to be quite persistent. As a result of the construction boom of new and the extension of existing convention and exhibition centers, the number of large facilities for trade fair activity grew drastically during the 2000s. Between 2009 and 2011 
alone, the number of convention centers with more than 50,000 square meters indoor exhibition space increased from 31 to 38 and the total exhibition space in these centers increased by 38.2 per cent from 2.5 to 3.4 million square meters (Table 1). Guangzhou and Shanghai clearly had the largest indoor exhibition space and added substantial new trade fair capacity during this time period. ${ }^{1}$

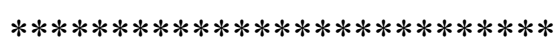

Table 1 about here

Associated with the convention center building boom, the number of trade fairs grew almost exponentially. According to Guo (2012), the total number of events in China increased from 4,600 to 6,000 between 2009 and 2011. Shanghai, Beijing and Guangzhou were the cities with the largest number of trade fairs. In 2007, an estimated 924 trade fairs were held in these cities (AUMA 2008) - a number that increase to 1,205 in 2009 (Wang and Guo 2010). Increasingly, trade fair activity also spread to inland and western Chinese cities, such as Chengdu, although Shanghai, Jiangsu, Beijing, Guangdong and Zhejiang were still the core provinces of the trade fair business. In this study, one coastal and one inland city with substantial convention center capacity were chosen to study the development of trade fair activities: Shanghai and Chengdu.

\footnotetext{
${ }^{1}$ The development in Shanghai demonstrates this. Of the 17 exhibitions halls of the Shanghai New International Expo Centre (SNIEC) - established in 1999 - 6 were built between 2004 and 2007 and another 6 in 2010 and 2011. From 2010 to 2011 alone, the overall indoor exhibition space almost doubled from 103,500 square meters to about 200,000 square meters in early 2012 (Geduhn 2012). Furthermore, another - even larger - trade fair center is scheduled to be completed by 2015 close to Shanghai's former airport Hongqiao. The Hongqiao Convention and Exhibition Centre will have an indoor exhibition space of 400,000 square meters (Shi 2012).
} 
While it appears that second-tier cities have become increasingly important as trade fair destinations during the 2000s (Jin et al. 2010a), no systematic information exists regarding the types of trade fairs that develop and the nature of interaction that takes place during these events. Using this as a starting point, the goals of this paper are threefold: The paper first aims to explore the nature and structure of national/international trade fairs in China in terms of participants and their agendas. The second goal is to investigate whether the nature of communication and interaction during trade fairs resembles that of international events in Europe and North America. Third, it is aimed to explore the variability that exists between Chinese trade fairs in different parts of the country.

The remainder of this paper is structured as follows: Section 2 discusses the applicability of the concept of temporary clusters to the Chinese trade fair context and develops hypotheses that guide the analysis. Section 3 presents the methodology of the study, while Section 4 discusses the results of 102 interviews conducted in Shanghai and Chengdu. Section 5 summarizes the most important findings and concludes.

\section{Trade Fair Ecologies and Temporary Clusters}

Since the mid 2000s, a body of literature has developed that does not view trade fairs as pure marketing events where producers meet buyers, but rather emphasizes how international trade fairs provide an important instrument to enable, initiate and canalize knowledge and information flows over distance (Borghini et al. 2004; 2006; Maskell et al. 2006). From a knowledge-based perspective, particularly business-to-business events are key in developing new markets, initiating network relations and coordinating interaction between distant permanent locations (Prüser 2003; Bathelt and Schuldt 2008; Ramirez-Pasillas 2008). These events can be analyzed as temporary clusters (Maskell et al. 2006) where firms from an entire value chain or 
technology field meet over a few consecutive days to discuss the development of markets, products, technological innovations, regulations and all sorts of news regarding their business thus establishing a microcosm of this industry (Rosson and Seringhaus 1995). At the same time, these transient spaces are social events (Norcliffe and Rendace 2003; Entwistle and Rocamora 2006; Weller 2008) that rely on and benefit from recurrent themes and technological progress in cyclical and related meetings every few months (Godar and O'Connor 2001; Power and Jansson 2008). As a consequence, these are places where focused industry communities are strengthened, shaped and reproduced (Bathelt and Schuldt 2008).

Like permanent industry clusters (Malmberg and Maskell 2002), trade fairs are characterized by distinct vertical and horizontal communication patterns. Vertical interaction with suppliers and customers consists of information exchange about recent trends, experiences and requirements for future products and services. Although meetings with existing and potential new suppliers take place to discuss technological changes in product specifications, developments in markets and future conditions, the key component of such meetings is systematic customer contact (Golfetto and Rinallo 2011). Firms intensify social relations with their customers and address new customers to market their products, display new developments and discuss potential contracts (Backhaus 1992; Meffert 1993). Meetings between producers and their customers are an important source of information for further product improvements.

Trade fairs also bring together firms that compete against one another and normally do not interact. At this horizontal level, they provide multiple opportunities for firms to observe and compare their products and strategies with those of their competitors (Borghini et al. 2004). Firms systematically look through the exhibits of their competitors and make note of product designs, innovations and new fields of application. Part of the screening and observation process 
is less systematic, as firms try to get an overview of what is going on in their business and what trends exist (Bathelt and Schuldt 2008).

Related interaction and learning processes during trade fairs benefit from the fact that the agents participating in these events share a similar institutional basis with respect to their industry and its products and technologies. They are members of communities of practice and epistemic communities with partly overlapping and complementary knowledge bases (Wenger 1998; Knorr Cetina 1999). This provides a basis for common interpretations and mutual understandings (Bathelt and Schuldt 2008). As a result of intensive, often short communication between the agents during these events - and supported through their cyclical nature international trade fairs serve to deepen the institutional basis of the respective value chain.

The learning processes during these events associated with learning by interaction and learning by observation enable firms to evaluate their products and technological sophistication in relation to what goes on in other parts of the world (Sharland and Balogh 1996; Borghini et al. 2006). Along with the information gathered from customers and suppliers, firms receive a broad overview of state-of-the-art technologies and market trends which help to review their own practices and strategies (Rosson and Seringhaus 1995). This is of great important in the development and refinement of business strategies, decisions about the production program and innovation and eventually impacts the spatial division of labor.

Overall, the vertical, horizontal and institutional cluster dimensions enable intensified circulation of information and knowledge between trade fair participants. New ideas and projects in an industry or technology field can be identified through scouting and monitoring. This is possible because important information, news, trends and rumors make their rounds through the 
event. The resulting information and communication ecology can be characterized as temporary 'global buzz' (Maskell et al. 2006; Schuldt and Bathelt 2011).

While this conception characterizes trade fairs as events that are key in processes of global knowledge creation and circulation, it may not be easily applicable to less-developed or developing contexts where trade fairs are in the process of formation. Existing literature on trade fairs in China highlights that these events appear to be important, on the one hand, for Chinese producers in meeting foreign buyers, and, on the other hand, for foreign producers to access the Chinese market. The former Canton Fair in Guangzhou - which is now one of the largest biannual trade fairs worldwide with about 10,000 exhibitors from China and 200,000 visitors from over 100 countries - developed since the late 1950s into a mega event designed to promote export sales by enabling Chinese producers to make business with foreign buyers and foreign buyers to order low-cost products (Jin and Weber 2008; Canton Fair Online 2012). As emphasized by Fu et al. (2007: 84), "[w]ith its transactions that account for about one-fourth of China's general export trade every year, the fair ... has served as an important platform for promoting products by small and medium-sized Chinese exporters". Although its importance with respect to export trade likely decreased during the late 2000s, the China Import and Export Fair is clearly still an important marketplace. Powell (2007) described the sales activities and "buzz" during this trade fair emphasizing that Chinese entrepreneurs attending the event particularly liked to do business with US-based firms because these would pay 30 per cent of the order value up-front. This business practice reduced the overall risk of Chinese firms which, at that time, often did not have much capital, while customers from other countries apparently preferred transactions based on letters of credit which meant a much higher risk for Chinese exhibitors. Based on similar findings on the dominance of sales activities, Fu et al. (2007) 
suggested that particularly small and medium-sized firms in China may neglect non-selling objectives when they attend trade fairs.

While the former Canton fair has developed into a critical event for both exporters and importers, anecdotal evidence and occasional studies of other fairs also suggest that Chinese trade fairs are very strong in terms of sales and contractual components, while innovation plays only a minor or subordinate role. Kay (2005: 15), for instance, emphasized in his analysis of Chinese trade fairs dynamics that "international conventions and exhibitions (C\&E) are [now] mostly focused on infrastructure, machinery, and imports into China. The C\&E centers in Hong Kong and Guangzhou ... concentrate on the exports of consumer commodities from China."

In a comparison of the layout and activities during major plastics trade fairs in China, Germany and Japan, Yeung (2004) made interesting comparisons based on participatory observation. He noted that almost all global players of the industry showed their products in China, yet that their exhibits were quite different from those at other fairs. He noted that some "exhibitors only had a small, storefront booth. Most press makers had only two or three machines in their booths...", as opposed to German and Japanese fairs where the entire production program would be showcased. Yeung (2004) further observed that the "materials being molded on the shop floor were relatively low tech, with high-volume, commodity materials dominating, whereas in Japan machine makers focused on running more advanced, difficult-to-mold materials." German exhibitors, due to the high costs of participation ${ }^{2}$ attempted to exhibit as many items in their small booths as possible creating rather crammed exhibits with

\footnotetext{
${ }^{2}$ According to Kay (2005), trade fair participation for foreign exhibitors tended to be substantially more expansive than for domestic exhibitors, related to governmental influences in these events.
} 
little aesthetic ambition. Furthermore, some foreign exhibitors promoted their recent innovations, but did not actually exhibit them.

In general, innovation was seemingly not a major focus in Chinese fairs. Even the exhibits of Chinese participants were different from the ones they would show in other countries. According to Yeung (2004), they were represented well "but not with the flurry and focus" they would demonstrate at trade fairs in Japan and Germany. As such, Chinese trade fairs were not focused on leading-edge innovation, but concentrated on supporting existing products primarily addressed towards the Chinese market.

At the same time, another set of studies pointed at inefficiencies of Chinese trade fairs that would have an impact on the interaction processes. Skov (2006), for instance, criticized the inefficient organization and unprofessional management of trade fairs, as well as unprofessional participants at these events. Similarly, Jin et al. (2010b) concluded that few trade fairs in China had the character of flagship fairs and criticized opportunistic behavior of trade fair organizers, sometimes creating unnecessary confusion and supporting misleading expectations of participants. Kay (2005) further suggested that the boom of new trade fair centers was primarily driven by political goals instead of real demand. Accordingly, this resulted in over-capacities and low utilization rates of such facilities, especially in second-/third-tier trade fair cities (Jin et al. 2010b). All of this suggests that Chinese trade fairs would be unlikely to perform a strong role in knowledge creation, network generation and inter-firm learning processes as suggested in the model of temporary clusters.

Despite this evidence of potentially counterproductive structures, we cannot expect that such characteristics remain unchanged over time. In fact, the growth processes in the Chinese economy likely put a lot of pressure on dynamic adaptation in the trade fair business. Analyzing 
the motivations and satisfaction of trade fair attendees, for instance, Bauer et al. (2008) found in a case study in Hong Kong that there were no significant differences between foreign and domestic participants. Furthermore, some trade fairs now seem to develop into global meeting places for entire value chains. As China has become the most important market for automobiles, "Auto Shanghai" developed into a key event of the industry, as the analysis of Bartsch (2011) suggests. Despite a strong emphasis on sales activities, Fu et al.'s (2007) study of small and medium-sized firms suggests that exhibitors also follow non-selling objectives in their trade fair participation (Sharland and Balogh 1996). In fact, if we follow Maskell's (2012) conceptualization of how to access remote knowledge, we would expect that trade fairs will become major places of knowledge transfer and acquisition in the future, as China is characterized by high uncertainties regarding which type of knowledge is useful or required in innovation, where to look for it and who to approach.

From all of these considerations, we hypothesize that Chinese trade fairs are less innovative than flagship fairs in other countries but that knowledge exchanges between participants, as described in the temporary cluster model, become more important and international over time (H1). We also expect that the importance of negotiations of sales and contracts decreases, while aspects of networking and customer interaction gain in importance (H2). At the same time, it can be expected, however, that substantial differences exist between different events in China as the trade fair business is still in its formative stage (H3). Particularly, we expect that trade fair organization and interaction patterns are less sophisticated and complex in inland cities as opposed to coastal cities (H4). 
Before presenting the results of our empirical study of Chinese trade fairs in different cities, the next section discusses the methodology applied in terms of case selection, sampling and interview design.

\section{Methodology}

As our goal was to explore the state and development of the trade fair business in China, we conducted a comparative, interview-based study of three trade fairs in established manufacturing sectors in which such events traditionally play an important role. Following a close-dialogue approach (Clark 1998), our research was primarily qualitative and explorative in nature (Eisenhardt, 1989). We chose to investigate trade fairs in both a highly-industrialized coastal city and a less-developed inland city. Following earlier studies, our research focused on business-to-business fairs (Borghini et al. 2006, Bathelt and Schuldt 2008, Ramirez-Pasillas 2008), as these events allow us to draw conclusions about the economic impacts of these events on wider production networks.

The first event selected was China International Industrial Fair (CIIF), which is set in the context of one of the most developed Chinese agglomerations in Shanghai. It takes place at an annual basis in the Shanghai New International Expo Centre (SNIEC), located relatively close to the international airport in Pudong (Erwin 2003; China-Fairs.com 2012). CIIF is one of the largest manufacturing fairs in Asia with a total of 1,653 exhibitors and 116,800 visitors in 2010

(Table 2). The event is jointly organized by the several national ministries and academies, as well as the city of Shanghai. It can thus be characterized as a state-led trade fair involving, among others, the National Development and Reform Commission, the Chinese Academy of Engineering and the Ministries of Commerce, Industry and Information Technology, Science and Technology and Education (China International Industry Fair 2011). CIIF is also one of the most 
international trade shows in China in terms of exhibitor participation, with 34 per cent of all exhibitors originating from overseas, especially from Japan, Germany, Taiwan and the USA. In contrast, CIIF has only few international visitors. It is noteworthy that the overall number of exhibitors at CIIF decreased by 16 per cent in recent years, from 1,968 in 2006 to 1,653 in 2010 (China International Industry Fair 2009, 2011). This should, however, not be misinterpreted as a loss in importance, as, for instance, the number of visitors increased steadily. Especially, the number of foreign exhibitors increased by 71 per cent from 331 to 566 . According to our interviews, the reduction in Chinese exhibitors can be viewed as a consolidation process as domestic firms that originally had different expectations in participating at CIIF were unsure of how to utilize such a fair.

Table 2 about here

At closer investigation, it becomes clear that CIIF is not a homogenous event but an amalgamation of six different trade fairs - or a multi-sector event - spanning the fields of industrial automation, energy, environmental protection, metalworking/CNC machinery, information communication technologies and scientific/technological innovation. These individual fairs took place in all nine exhibition halls of SNIEC covering a total indoor exhibition space of 103,500 square meters (Table 2). We chose to explore two of the trade fairs with different technology focus more thoroughly and conducted interviews with exhibitors during these events. The trade fairs chosen for this study were the Metalworking and CNC Machine Tool Show (MWCS) and Information \& Communication Technology Show (ICTS). Of these, MWCS was clearly the core of CIIF, occupying three exhibition halls. Arguably, most of 
the visitors of CIIF were attracted to this trade fair. In contrast, ICTS took place in only one exhibition hall and was characterized by a much lower share of international exhibitors (16 per cent) as opposed to MWCS.

The third trade fair chosen was the 12th China International Exhibition on Gases Technology, Equipment and Application (IG China) in Chengdu. The city, which is located in Sichuan province, is sometimes viewed as a gateway to China's West. It has a modern suburban exhibition center that is connected to the city core through a new subway line. The Chengdu New International Exhibition \& Convention Center consists of nine exhibition halls, covering 55,000 square meters of indoor exhibition space (Kay 2005; AUMA 2008). The trade fair center covers a total construction area of 200,000 square meters and has a modern infrastructure and close-by hotels (Chengdu Municipal Government 2008). With an exhibition space of 12,000 square meters, 220 exhibitors and 10,000 visitors, IG China was about the size of ICTS (Table 2). Although foreign attendees were a minority, firms from Germany, the USA, Russia and other countries were among the exhibitors. IG China is a trade fair that is organized by the China Industrial Gases Industry Association - the corresponding national industry association. The show is an annual event that took place in Chengdu for the first time in 2010 (Cockerill 2010; China International Exhibition on Gases Technology, Equipment and Application 2010). In the years before and after, the event took place in Beijing, and is scheduled for Nanjing in 2012.

During the three trade fairs, we conducted an explorative study using a qualitative research design that involved semi-structured interview and systematic observation. Firms to be interviewed were chosen randomly during trade fairs in such a way that the entire exhibition halls were covered while ensuring that, on the one hand, small and large and, on the other hand, domestic and foreign firms were included. Firms to be included were approached during fair 
hours and asked to take a few minutes to participate in the study. A total of 102 interviews were conducted in November 2010, with 45, 24 and 33 interviews at MWCS, ICTS and IG China, respectively (Table 3). Overall, we had a very high response rate of 89 per cent with only 13 rejections in total. A somewhat higher rejection rate of 23 per cent at ICTS was probably due to the problematic set-up of the trade fair that left many exhibitors dissatisfied, as discussed below. Interviews were conducted in English, Chinese or German with the most senior decision-makers present at the exhibition booths, usually involving executives, sales managers or engineers.

Table 3 about here

Interviews took on average 10 to 15 minutes and were based on a structured interview guide. The questions asked were divided into five sections. The first section focused on the characteristics of the trade fair and the main reasons for attendance. The second and third sections contained questions about customer and competitor interaction during the fair, including the types of visitors, customers and competitors met and the topics discussed. In the fourth section, interviewees were asked to qualify the outcomes of their trade fair participation, before additional information was acquired in the last section about the size, age, country of origin and ownership structure of the firms.

In terms of the firms' structure, there were no fundamental differences across the three events. Between 53 per cent (MWCS) and 68 per cent (ICTS and IG China) of the firms interviewed were of Chinese origin (Table 4). The share of foreign exhibitors in the sample was somewhat elevated compared to the overall population (compare Tables 2 and 4), since we were particularly interested in the views and evaluations of foreign firms, which were able to compare 
the state of Chinese fairs with events in their home countries. The range of countries at MWCS, from which exhibitors were drawn, was broader than at the other fairs, with a particularly high proportion of exhibitors from Europe. Between 35 percent (ICTS) and 50 per cent (IG China) of the firms interviewed were privately owned Chinese firms, although state-owned firms and state holdings were present at all events (Table 5). Due to nature of the Chinese oil and gas extraction business, the presence of state-owned firms and state holdings at IG China was larger compared to the other trade fairs. Interestingly, relatively few joint venture firms presented their products at the three events. Many of the firms (34 to 41 per cent) were relatively young being established in the 2000s (Table 6). Overall, 65 to 77 per cent were less than 20 years old, although 22-23 per cent of the firms interviewed at MWCS and IG China had already been established before 1970 . In the oil-/gas-related industry, almost a fifth of the firms had a very long tradition and were founded before 1900. Although many firms had less than 100 employees ( 27 to 39 per cent), the majority were medium-sized or large firms, with 22 per cent (IG China) to 41 per cent (ICTS) having at least 500 employees (Table 7).

Tables 4 to 7 about here

Aside from the interviews, we also conducted structured observations as a method to explore the nature of the events. Observations were structured according general characteristics of the trade fairs, the nature of exhibitors and visitors attending, the communication and observation processes witnessed, as well as unusual or peculiar behaviors and practices of participants. The observations were, if possible, noted during the fair hours and systematically written down in the form of a log at the end of the day. 
Having discussed the methodology applied and the data created, the next section will use this data to characterize the characteristics of the three trade fairs and the nature of interaction processes between different attendee groups.

\section{Trade Fair Dynamics in China}

Our empirical analysis turned out quite differently as hypothesized. In contrast with our expectations that were shaped by earlier media reports and studies, we did not find indication of older trade fairs facilities or shows that were disorganized or mismanaged. In contrast, it became clear that the trade fair business in China was "buzzing", that trade fair centers were heavily used and that the trade fair business developed rapidly with the establishment of new, highly modern trade fair and convention centers. As described below, we encountered mostly professionallyorganized shows that were not substantially different from trade fairs to be found in Europe or North America. As will be shown, these are neither import nor export sales shows but heterogeneous trade fairs with different goals, agendas and participant evaluations. The analysis that follows is based on both interviews conducted and observations noted.

\subsection{Metalworking and CNC Machine Tool Show (MWCS), Shanghai}

MWCS was clearly the largest and busiest of the trade fairs at CIIF (China International Industry Fair 2011), set-up in collaboration with the trade fair organizers from Hannover, Germany. In general, MWCS can be characterized as a broad machinery and manufacturing trade fair specialized on industrial machinery and equipment, $\mathrm{CNC}$ machine tools, plant engineering and all sorts of metal-related and metal processing applications. The exhibition spaces were characterized by a dense flow of visitors engaged in the scanning of material artefacts and discussions with exhibitors and other visitors about various characteristics of the 
products shown, their applicability and price aspects. Overall, the trade fair was different from what we had originally expected after studying reports about early trade fairs in China. Neither was MWCS a chaotic event, nor was the focus of activities on sales. In fact, although some remarkable differences existed between this fair and comparable trade fairs in Europe, the nature of knowledge exchange observed and the interaction patterns were not radically different from those at fairs, such as Hannover Messe or IFFA in Germany (Schuldt and Bathelt 2011). Despite this, the following deviations were noticeable:

First, the display of the most advanced technologies and the presentation of innovation at MWCS clearly played a smaller role than in European flagship fairs. Foreign exhibitors mentioned during the interviews that they did not show their latest, most advanced innovation and had smaller exhibits than in Europe or North America. Despite this, much of the discussions in the halls were about new developments in the industry and innovation trends spotted by firms. Most of the Chinese exhibitors did not describe themselves as innovation leaders but as highquality-medium-price producers. As one senior manager described it: "We are not Mercedes ... or Volkswagen, but we focus on our group of people. That is why we are so successful in Asia."

Second, direct sales activities were clearly going on at MWCS, but, according to our interviews, did not stand out as the focal motivation behind trade fair participation. Firms emphasized that MWCS was primarily an occasion to make direct customer contact on the Chinese market, from which sales could perhaps develop after the trade fair. Most foreign exhibitors were optimistic about the prospects of follow-up business after the fair or in the future. In sum, the reasons to participate in the trade fair were quite varied: One group of exhibitors emphasized the goal to promote their brand in the Chinese market (13 firms interviewed), while others aimed to strengthen their image ( 7 firms). A second large group of exhibitors expressed 
the wish to establish new customer contacts (18 firms), instead of immediately selling products. ${ }^{3}$ Chinese exhibitors were aware that customer relationships need to be built over time and that the fair was an important step in this process. The owner of a small machinery firm explained: "We want to go step by step. We introduce ourselves, and make the customer believe that our quality is o.k. - and step by step and demonstrate the machine."

Third, different from major exhibitions such as Hannovermesse, the exhibition halls were not primarily set up for passive showcasing. Many firms had their equipment and machines in operation to directly demonstrate their performance. As a consequence, many parts of the exhibition halls at MWCS were quite noisy, and it was often difficult to understand what others were saying. All in all, parts of the exhibition halls had the atmosphere of an actual factory or workplace associated with the smells of oil, fumes and heat development. At the same time similar to European and North American events - the halls had stages with (often loud) live music, fashion shows and other events to create a spectacle and make people stay.

Fourth, MWCS was not an export fair. A large proportion of the visitors originated from the Yangtze Delta region, while exhibitors came from across China with a substantial proportion of international exhibitors (Tables 2 and 4). Yet, it would be misleading to characterize MWCS as an import fair. Many firms pointed out that the fair would provide them with an excellent overview of competition. While some firms, as one manager expressed it, “... already know all competitors in China", others used this to reflect about their own product and corporate characteristics. The owner of a small Chinese producer recalled his impressions as follows: "I

\footnotetext{
${ }^{3}$ This confirms findings from a survey of 123 small and medium-sized export exhibitors by Fu et al. (2007), which indicate that non-selling functions, such as finding out about customer preferences and probing industry dynamics, were among the objectives of more than $70 \%$ of the exhibitors that were satisfied with their trade fair performance. In contrast to their study, however, sales functions were not important in our investigation.
} 
have already looked around at our competitors' exhibits and found many competitors provide some better products. I felt the pressure of competition.”

Fifth, aside from the official trade fair schedule, another hidden and unofficial exhibition existed. This developed and took place in the hallways of the exhibition space. Here, we encountered traders, representing Chinese firms from different, often distant parts of the country, who were walking through the exhibition halls looking out for potential overseas customers. As one of the authors was easily identifiable as non-Chinese, he was regularly approached by such traders. They were usually accompanied by one or two employees with larger bags or trollies in which they stored colorful advertising materials, as well as samples of the products they offered for sale on behalf of Chinese producers. They viewed us as international customers and acted as knowledge brokers to catch our interest and connect with their clientele. ${ }^{4}$ The firms they represented were seemingly focused on export activities and wanted to avoid the costs of officially participating in the fair. Possibly, these included firms that had participated in former years but stopped to do so, as the number of foreign visitors was too low. Not surprisingly, a common complaint among the traders interviewed, as well as among other Chinese exhibitors, was that there were not enough international visitors or foreign buyers. Some suggested that the international audience had decreased compared to prior years.

In sum, the nature of conversations and interaction at MWCS was similar to that at European or North American trade fairs. One foreign executive described the varied "buzz" of MWCS as follows: "While some firms look for potential customers and show new products and technology, others are innovative showing creative ideas". It seemed though that the classical

${ }^{4}$ Within a two-day period, we were approached by about 20 such traders in the MWCS exhibition halls, 3 of which we were able to interview. 
roles of exhibitors and visitors were quite inter-mixed: On the one hand, exhibitors spent a substantial amount of time to look through other exhibits in search for potential business or partners, and made direct contact with competitors. Several interviewees mentioned that contact with competitors was generally friendly, partly because competitors were often also engaged in complementary business and operated as suppliers or customers in these segments. On the other hand, the exhibition hallways were used by traders who, hidden as visitors, represented small and medium-sized producers from other Chinese regions to sell their products to foreign visitors and supply all sorts of information about the products. The corresponding knowledge flows in either case were remarkably similar, supporting the implications of Maskell's (2012) conceptualization that predict strong knowledge exchange/creation processes at trade fairs in China.

Exhibitors at MWCS were generally happy with the organization of the trade fair but complained about the cost of utilities that, according to a European producer, were substantially higher than those at Hannovermesse in Germany. Generally, foreign exhibitors also complained about the lack of Chinese business decision-makers, which was viewed to be a general problem in the country. As a senior manager of a Belgian firm mentioned, many Chinese decision-makers would not recognize the importance of trade shows and "often ... do not come to the show". According to a survey conducted by the fair organizers, MWCS still had a substantial share of decision-makers among its visitors compared to other trade fairs in the country. The organizers estimated that 23 per cent of the visitors were decision-makers and another 55 per cent would, at least, be partially involved in or propose to corporate decision-making processes (Metalworking and CNC Machine Tool Show 2011). ${ }^{5}$ Others noted that the fair had decreased in size over the

\footnotetext{
${ }^{5}$ It is unclear, however, how reliable this data is.
} 
years but this appeared to be the consequence of a consolidation process among Chinese exhibitors and not an indication of decreasing importance.

\subsection{Information \& Communication Technology Show (ICTS), Shanghai}

Although taking place in the exhibition hall adjacent to MWCS, ICTS was a completely different event with much fewer exhibitors and visitors (Table 2). ICTS is a new trade fair in the field of information and communication technologies, launched in the context of CIIF for the first time in 2010 (Information \& Communication Technology Show 2010). Compared to MWCS, the exhibition space, first, was much quieter as there were no machines that were in operation. Second, the exhibitions hall appeared very spacious with few people wondering around and even fewer people approaching the exhibitors directly. This did not change during the course of the fair. Thirdly, the set of exhibitors appeared very heterogeneous without a clear focus. In an apparent attempt to fill the exhibition hall, the organizers had allowed exhibits that were hardly related to the themes of the show and primarily had the character of standard product advertisements, for instance booths advertising cellular phones with new contracts or automobile firms showcasing their latest models. Fourth, in wandering around the exhibits and observing other people, we had the impression that relatively few people had entered CIIF to specifically explore the information and communication technology exhibits, but had attended another fair and just came to see what ICTS was about.

One exhibitor expressed in the following way, what also others thought about the audience: "Many of them are not very professional. In fact, many of them do not know us very well.” Another added frustrated: “... so it is meaningless!” Communication between exhibitors and visitors was neither very specific nor intensive. A typical response of an exhibitor regarding interaction with customers was: "No, we have not learned anything [from our customers]." 
Similar comments were given with respect to interaction with competitors. One Chinese producer criticized that the "... fair is totally driven by the government. Maybe ... [other] halls are better, but look at our hall. It is full of all kinds of companies. It should be more professional."

Not surprisingly, many of the exhibitors we talked to had a negative impression of ICTS and described it as a disappointing event. Most firms emphasized that they had come to the fair to find new customers ( 21 firms) or popularize the firm and its products ( 9 firms). To launch the fair, the organizers and government had approached firms directly and actively recruited participants, especially larger and state-owned firms. Among the recruited participants were also representatives of information technology parks who did not present products and technologies but simply introduced and advertised their parks. Clearly, numerous exhibitors had come with rather different expectations influenced by the organizers' prior descriptions. Overall, most firms had negative feelings about the event and, as a consequence, people were less willing to give us an interview (Table 3). It seemed that ICTS together with the Scientific \& Technological Innovation Show (STIS) ${ }^{6}$ that took place in another adjacent exhibition hall were primarily setup to extend the scale and scope of CIIF as a broad multi-sectoral trade show, similar to the flagship fair Hannovermesse (Schuldt and Bathelt 2011). Overall, it appeared that this concept did not (yet) function well. The attending exhibitor and visitor groups were clearly too heterogeneous to allow for relationship building, market penetration or product-related learning to take place. Many interviewees pointed out that ICTS would not compare with the more professional character of a similar trade fair in Guangzhou.

${ }^{6}$ STIS hardly had the character of a trade fair. It appeared to be primarily a platform for universities and research organizations to demonstrate their accomplishments, as well as for state-owned firms to "show face". 


\subsection{China International Exhibition on Gases Technology, Equipment and Application (IG China), Chengdu}

When we went to IG China, we expected a different trade fair from the ones studied in Shanghai, i.e. one that would be reminiscent of early trade fair development. Again, we were surprised with what we found. Not only were the facilities and infrastructure around the trade fair new and well-designed, also, the organization of the event itself was professional and well received by most interviewees. ${ }^{7}$ Even though the fair had a different character from the other fairs investigated, its set-up was not much different from trade fairs in Europe or North America. When we attended IG China, the entire exhibition complex was "buzzing" with several other trade fairs/conventions taking place at the same time, each one occupying one exhibition hall.

IG-China is a specialized trade fair organized by the Chinese industry association of the gas industry that took place in 2010 in Chengdu for the first time (Cockerill 2010). Although Chengdu is of increasing importance in the gas industry with a fast-growing urban economy, some exhibitors were surprised that the city was chosen as a site for IG China. They mentioned that some Chinese market leaders did not participate in the fair because of the locational choice. Aside from the location, the organizers had made substantial efforts to organize the event professionally and make sure that there was a constant flow of visitors. They actively recruited visitors to attend IG China and organized bus tours for firm representatives, especially in the

\footnotetext{
${ }^{7}$ Since a substantial part of China's overall trade fair and exhibition space was built after 2000, the
} respective venues are easily accessible, have a modern infrastructure and are well-equipped. Between 2002 and 2011 , the available indoor exhibition space of SCNIEC has, for instance, almost tripled while the turnover rate has more than doubled. The turnover rate in 2011 was 32, which means that the entire exhibitions space of SNIEC was rented out 32 times in that year. This is one of the highest turnover rates in the world and more than twice as high as that of most European trade fair centers (Bartsch 2012; Geduhn 2012). 
opening days. The final day was much quieter with Chinese exhibitors already removing their exhibits.

In general, IG China can be described as a specialized trade fair for the gas industry with a particular focus on the equipment side. The event was not a regional fair, as we had expected, but an event of national importance with exhibitors and visitors from all parts of China with a regional gas industry. During the event, we hardly noticed foreign visitors, except for a few Indian representatives, but about 16 per cent of the exhibitors originated from foreign countries, such as Germany, the USA and Russia (Table 2). It took us a while to understand that the nature and core focus of the event was different from what we had anticipated. Although some sales contracts were apparently signed or prepared during the event, as indicated by our interviewees, IG China was clearly not a sales fair. Neither did exports nor imports play a significant role. Since IG China took place in a mature industry context with many long-established firms (Table 6) that knew each other's product offerings and activities extremely well, innovation did not play a great role. As one interviewee expressed it: "It is not about innovation here!" At closer investigation, three groups of exhibitors were identified that had different expectations and displayed different interaction patterns:

The first group of exhibitors (about half of the firms interviewed) were closely related to the core of the gas equipment business. They evaluated the fair as a rare specialized event that enabled them to get together with their specific core customers. A foreign manager therefore suggested: "This fairs is a good way to access the Chinese market." Nonetheless, most interviewees agreed that this was not a place to generate new business, which would usually require a much longer preparation. An important motivation of the exhibitors seemed to be to reinsure existing customers about their ongoing relationships, and vice versa. One senior 
engineer of a Chinese equipment maker described: "The first thing is to demonstrate the firm, and then we make friends with the new customers. But after many times of participation, it is not easy to find new customers. So, the main purpose is to demonstrate ourselves. When old friends see us, they say: 'O.k., you are still alive!'.” The firms used this event also to update their information about direct competitors and systematically visited other booths and talked to the corresponding personnel. Generally, they already knew the competitors and many of their representatives. As firms often had product portfolios that were partly overlapping, competitors were also suppliers and/or customer. As a result, the exhibitors at IG China were, at the same time, important visitors. One Chinese executive explained: "30 per cent of the exhibitors are our customers. We mainly introduce the new products to them."

The second group of exhibitors (a quarter of the firms interviewed) - among those foreign firms that had known the Chinese markets for a long time - did not expect much from the event in terms of new business or knowledge about innovation, but were primarily there "to show face", as several interviewees emphasized. One foreign manager described the fair as "the window for people who know the market”. Firms emphasized that this was helpful in developing and extending social relations both with existing customers, as well as with competitors. Several managers described the network-building character of IG China and suggested that the relatively isolated suburban location and the nearby hotels generated a context where exhibitors would constantly run into one another, both in- and outside the exhibition halls. As one Chinese executive described: "Old customers just come here and chat about good performance of our products, and show the will to keep in touch.” Relationship building also included competitors, as one executive emphasized: “... we view our competitors as partners. Although every firm has some concerns, the improvement of the industrial chain is more important [than fierce 
competition]." Another interviewee added about competitors: "We will build good relations with them." One senior manager of a foreign firm explained how they used this fair as an occasion to deliberately try to improve relations with a close competitor through mingling during after-fair hours and having joint dinners. This had been successful and led to a more relaxed atmosphere between representatives of both firms. Firms agreed that the generation of new networks during IG China would, however, be less likely.

The third group of exhibitors (another quarter of the interviewed firms) were somewhat outside the main focus of the trade fair and had come with different expectations. In contrast to what had been suggested by the fair organizers, they did not meet relevant customer groups and had no business during the fair. They thought IG China was somewhat useless for them and questioned that they would come again. They were also more negative about the concept of the fair.

The findings about the different customer groups were supported by the fact that firms generally did not describe themselves as cost-oriented producers. They emphasized quality/brand (9 firms) or performance-price ratios (12 firms) as key to their success. Clearly, the networking potential realized during IG China seemed to be particularly useful for small and medium-sized firms and, according to one interviewee, helped them to stabilize their market position. Also, established firms enjoyed the specialized character of the show which helped them to update knowledge about the development of the Chinese market. Not surprisingly, the third group of exhibitors had the most negative impressions of IG China, complaining that the event was too 
specialized, that opportunities for dining were not varied enough, that hygiene standards were low and that the logistics of the location were difficult. ${ }^{8}$

Overall, the three trade fairs turned out to be quite different from what we had expected. These were not primarily sales events or shows with a specific import or export focus but modern professional trade fairs that relied on differentiated knowledge and information flows and processes of relationship building and maintenance, albeit with rather different structures and practices among the trade fairs investigated. This will be further evaluated in the conclusions.

\section{Conclusions}

The goals of this paper were to explore the nature of information and communication ecologies at large national/international trade fairs in China, compare them with foreign trade fairs and explore the regional variability of such events in China. While existing studies and reports suggest that these events are very different from leading European and North American fairs, our hypotheses took into account that the nature of the trade fair business is rapidly changing, leading towards modern trade fair designs. Our empirical study conducted in 2010 was based on a qualitative research design that included two trade fairs in Shanghai and one in Chengdu. Regarding our original hypotheses, the main findings can be summarized as follows:

(i) The results of our interviews support hypothesis H1, suggesting that innovation is indeed less important as, for instance, in the context of European flagship fairs. While market access/penetration appear to be important goals of trade fair participation, Chinese fairs are still

\footnotetext{
${ }^{8}$ Especially females and foreign managers complained about such shortcomings which were indeed not comparable with the standards at similar European and North American events. In this context, it should be emphasized that IG China was almost exclusively a male domain with few female managers or supportive personnel.
} 
far from becoming leaders in innovation. Nonetheless, knowledge exchange about new developments and innovation trends in the industry, as well as aspects of relationship building/maintenance were at the core of these events. Compared to early descriptions in the literature where these processes were not prominent, aspects of knowledge circulation seemed to have gained substantial importance at large national/international trade fairs in China. In fact, following Maskell's (2012) conceptualization, we expect that trade fairs become key places of knowledge creation, since the uncertainties of who to approach where and for which kind of knowledge are extremely high in the intransparent Chinese market.

(ii) Hypothesis H2 was also supported. Direct product sales and contract negotiations took place during the explored trade fairs but were less important than implied in the literature. Although trade still played a significant role during some of these events, aspects of knowledge generation and network building were more prominent than previous literature suggested.

(iii) Further, this study found that the nature of the events varied substantially, giving these events a completely different meaning within their respective industry context. While MWCS was focused on knowledge exchange, ICTS involved very little interaction at all, and IG China was primarily oriented towards relationship building. This confirmed hypothesis H3. It appears that the participants of general industry fairs aim to find new partners during these events and extend their networks, while participants in specialized fairs pay more attention towards deepening and maintaining existing networks and relationships.

(iv) In contrast, we were not able to confirm hypothesis H4 as our cases clearly showed that inland fairs are not automatically less developed or less well-organized than events in the coastal cities. Since cities in the coastal region are usually better connected to the global economy in terms of transportation and communication infrastructure, they likely have a higher 
international participation and are more open to foreign participants than trade fairs in inland cities. While we can thus expect that more leading firms from Europe or North America participate in coastal city trade fairs, trade fairs in Western China likely have a higher attendance of firms from neighboring countries, such as India or Russia, with easy access to the region.

The fundamental dynamics of trade fair development in China that led to the structures explored in this paper are increasingly driven by industry associations and investments of local governments, thus reducing the influence of the central government. Such initiatives are often targeted towards city marketing/branding and regional economic development. Most trade fairs are overwhelmingly characterized by Chinese attendance. Because of the large size and fast development of the Chinese economy, the majority of participants originate from within China (even if trade fairs, such as MWCS, have a significant share of foreign exhibitor). ${ }^{9}$ As a consequence, it becomes more difficult to apply classification schemes that distinguish between international, export, import and regional/national events (e.g. Rinallo and Golfetto 2011) to the country's trade fair economy without applying additional knowledge regarding an industry's entire trade fair sequence. In the future, we might even expect the rise of global flagship fairs in the country that might still be dominated by national participation.

\section{Acknowledgements}

*To be added later

\footnotetext{
${ }^{9}$ An exception is the China Import and Export Fair in Guangzhou. In the spring fair 2012, 46.1 per cent of nearly 210,000 buyers came from outside Asia - 38,100 of which from Europe and 34,200 from North America (Canton Fair Online 2012).
} 


\section{References}

Allix, A. (1922): The geography of fairs: Illustrated by old-world examples. Geographical Review 12: 532-569.

AUMA - Ausstellungs- und Messeausschuss der deutschen Wirtschaft (2008): Messemarkt China (Trade Fair Market China). Berlin: AUMA. Available online: http://www.auma.de/_pages/d/04_MessemaerkteAusland/0402_Laenderprofile/040215_ Kanada/04021501_Uebersicht.aspx (November 20, 2010).

AUMA - Ausstellungs- und Messeausschuss der deutschen Wirtschaft (2009), Die Messewirtschaft: Bilanz 2008 (The Trade Fair Economy: 2008 Balance), Berlin: AUMA.

Backhaus, H. (1992): Investitionsgütermarketing (Investment Goods Marketing). München: Vahlen.

Bartsch, B. (2011): Vorfahrt für China (Right of way for China). Frankfurter Rundschau, April 20 , p. 15.

Bartsch, B. (2012): Marktplatz China (Marketplace China). Frankfurter Rundschau, April 23, p. 12.

Bathelt, H. and Schuldt, N. (2008): Between luminaries and meat grinders: International trade fairs as temporary clusters. Regional Studies 42: 853-868.

Bathelt, H. and Spigel, B. (2012): The spatial economy of North American trade fairs. Canadian Geographer 56: 18-38.

Bauer, T., Law, R., Tse, T. and Weber, K. (2008): Motivation and satisfaction of mega-business event attendees: The case of ITU 2006 in Hong Kong. International Journal of Contemporary Hospitality Management 20: 228-234.

Borghini, S., Golfetto, F. and Rinallo, D. (2004): Using Anthropological Methods to Study Industrial Marketing and Purchasing: An Exploration of Professional Trade Shows. Paper presented at the Industrial Marketing Purchasing Conference, Copenhagen.

Borghini, S., Golfetto, F. and Rinallo, D. (2006): Ongoing search among industrial buyers. Journal of Business Research 59: 1151-1159.

Canton Fair Online (2012): The Concluding Press Conference of 111th Session of the Canton Fair. Press Release, Guangzhou. Available online: http:www.cantonfair.org.cn/en/info/detail.aspx?oid=23962 (July 15, 2012).

CERMES - Research Centre on Markets and Industrial Sectors (2005): Trade Fair Observatory - International Trade Fair Report on Leading 5 European Countries (2005): Statistical Appendix. Milano: Bocconi University - CERMES.

Chengdu Municipal Government (2008): Exhibition and Convention Industries. Chengdu. Available from: http://www.chengdu.gov.cn/echengdu/news/detail.jsp?id=274977 (January 6, 2012).

China International Exhibition on Gases Technology, Equipment and Application (2010): IG China 2010. Chengdu. Available from: http://www.igchina-expo.com/home.php? (November 7, 2010).

China International Industry Fair (2009): Show Report: Nov, 2009. Shanghai. Available online: http:/www.ciif-expo.com/uploadfile/article/uploadfile/201004/20100421084034992.pdf (October 5, 2010).

China International Industry Fair (2011): After Show Report 2010. Shanghai. Available online: http:/www.ciif-expo.com/uploadfile/article/uploadfile/201012/20101231092500457.pdf (January 5, 2012). 
China-Fairs.com (2012): Shanghai New International Expo Center. Shanghai. Available from: http://www.china-fairs.com/exhibition-showroom/51.html (January 6, 2012).

Clark, G. (1998): Stylized facts and close dialogue: Methodology in economic geography. Annals of the Association of American Geographers 88: 73-87.

Cockerill, R. (2010): IG China moves to Chengdu for the first time. Gasworld, July 27. Available online: http://www.gasworld.com/ig-china-2010-moves-to-chengdu-for-thefirst-time/4928.article (October 5, 2010).

Eisenhardt, K. M. (1989): Building theories from case study research. Academy of Management Research 14: 532-550.

Entwistle, J. and Rocamora, A. (2006): The field of fashion materialized: A study of London Fashion Week. Sociology 40: 735-751.

Erwin, J. (2003): Messe Düsseldorf als Vorreiter im chinesischen Wachstumsmarkt (Düsseldorf Trade Fair Organizers as trendsetters in the Chinese growth market). In: Kirchgeorg, M., Dornscheidt, W. M., Giese, W. and Stoeck, N. (Eds.): Handbuch Messemanagement: Planung, Durchführung und Kontrolle von Messen, Kongressen und Events (Handbook of Trade Fair Management: Planning, Execution and Control of Trade Fairs, Conventions and Events). pp. 695-701. Wiesbaden: Gabler.

Expo-China.com (2012): Trade Fair and Convention Centers (Huizhan Changguan). http://www.expo-china.com/Web/hall/hall_main.aspx (February 17, 2012).

Fan, P. (2006): Catching up through developing innovation capability: Evidence from China's telecom-equipment industry. Technovation 26: 359-368.

Fu, H., Yang, G. and Qi, Y. (2007): Factors affecting trade show effectiveness for Chinese small and medium-sized exporters. International Management Review 3 (3): 84-96.

Geduhn, H.-J. (2012): Shanghai New International Expo Centre. Paper presented at the SNIEC, Shanghai, May 25.

Godar, S. and O'Connor, P. (2000): Same time next year - Buyer trade show motives. Industrial Marketing Management 30: 77-86.

Guo, J.-R. (2011): Blue Book of Convention \& Exhibition Economy. Annual Report on China's Convention \& Exhibition Economy 2011. Beijing: Social Sciences Academic Press (in Chinese).

Guo, J.-R. (2012): Blue Book of Convention \& Exhibition Economy. Annual Report on China's Convention \& Exhibition Economy 2012. Beijing: Social Sciences Academic Press (in Chinese).

Information \& Communication Technology Show (2010a): About ICTS. Shanghai. Available online: http://icts.ciif-expo.com/list.php?catid=169 (October 5, 2010).

Information \& Communication Technology Show (2010b): Main Figures of CIIF 2008. Shanghai. http://icts.ciif-expo.com/list.php?catid=174 (October 5, 2010).

Jin, X. and Weber, K. (2008): The China Import and Export (Canton) Fair: Past, present, and future. Journal of Convention \& Event Tourism 9: 221-234.

Jin, X., Bauer, T. and Weber, K. (2010a): China's second-tier cities as exhibition destinations. International Journal of Contemporary Hospitality Management 22: 552-571.

Jin, X., Weber, K. and Bauer, T. (2010b): The state of the exhibition industry in China. Journal of Convention \& Event Tourism 11: 2-17.

Kay, A. L. K. (2005): China's convention and exhibition center boom. Journal of Convention \& Event Tourism 7: 5-22. 
Knorr Cetina, K. (1999): Epistemic Cultures: How the Sciences Make Sense. Chicago: Chicago University Press.

Malmberg, A. and Maskell, P. (2002): The elusive concept of localization economies: towards a knowledge-based theory of spatial clustering. Environment and Planning A 34: 429-449.

Maskell, P. (2012): Accessing Remote Knowledge: The Complementary Roles of Trade Fairs, Pipelines, Crowdsourcing and Listening Posts. Paper presented at the conference on "The Rise of Trade Fair Ecologies in Asia-Pacific: Economic and Geographical Challenges", Shanghai.

Maskell, P., Bathelt, H. and Malmberg, A. (2006): Building global knowledge pipelines: The role of temporary clusters. European Planning Studies 14: 997-1013.

Meffert, H. (1993): Messen und Ausstellungen als Marketinginstrument (Trade fairs and exhibitions as a marketing tool). In: Goehrmann, K. E. (Ed.): Polit-Marketing auf Messen (Marketing Policy on Trade Fairs). pp. 74-96. Düsseldorf: Wirtschaft und Finanzen.

Metalworking and CNC Machine Tool Show (2011): Post Show Report. Shanghai. Available online: http://www.ciifexpo.com/uploadfile/mwcs/uploadfile/201012/20101217013749332.pdf (January 5, 2012).

Norcliffe, G. and Rendace, O. (2003): New geographies of comic book production in North America: the new artisans, distancing, and the periodic social economy. Economic Geography 79: 241-263.

Powell, S. (2007): Guangzhou, a microcosm of global trade. Barron's, March 12, p. 57.

Power, D. and Jansson, J. (2008): Cyclical clusters in global circuits: Overlapping spaces and furniture industry trade fairs. Economic Geography 84: 423-448.

Prüser, S. M. (2003): Die Messe als Networking-Plattform (Trade fairs as a platform for networking). In: Kirchgeorg, M., Dornscheidt, W. M., Giese, W. and Stoeck, N. (Eds.): Handbuch Messemanagement: Planung, Durchführung und Kontrolle von Messen, Kongressen und Events (Handbook of Trade Fair Management: Planning, Execution and Control of Trade Fairs, Conventions and Events). pp. 1181-1195. Wiesbaden: Gabler.

Ramirez-Pasillas, M. (2008): Resituating proximity and knowledge: Cross-fertilization in clusters by means of international trade fairs. European Planning Studies 16: 643-663.

Rinallo, D. and Golfetto, F. (2011): Exploring the knowledge strategies of temporary cluster organizers: A longitudinal study of the EU fabric industry trade shows (1986-2006). Economic Geography 87: 453-476.

Rosson, P. J. and Seringhaus, F. H. R. (1995): Visitor and exhibitor interaction at industrial trade fairs. Journal of Business Research 32: 81-90.

Schellkes, W. (2003): Entwicklung des Messewesens in der Triade (Development of the trade fair business in the Triad). In: Kirchgeorg, M., Dornscheidt, W. M., Giese, W. and Stoeck, N. (Eds.): Handbuch Messemanagement: Planung, Durchführung und Kontrolle von Messen, Kongressen und Events (Handbook of Trade Fair Management: Planning, Execution and Control of Trade Fairs, Conventions and Events). pp. 685-693. Wiesbaden: Gabler.

Schuldt, N. and Bathelt, H. (2011): International trade fairs and global buzz, Part II: Practices of global buzz. European Planning Studies 19: 1-22.

Sharland, A. and Balogh, P. (1996): The value of nonselling activities at international trade shows. Industrial Marketing Management 25: 59-66.

Shi, Y. (2012): World's biggest exhibition center set for Shanghai. China Daily, March 5, p. 13. 
Skov, L. (2006): The role of trade fairs in the global fashion business. Current Sociology 54: 764-783.

Sun, Y. and Wen, K. (2007): Uncertainties, imitating behaviors and foreign R\&D locations: Explaining the over-concentration of foreign R\&D in Beijing and Shanghai within China. Asia Pacific Business Review 13: 405-424.

UFI - The Global Association of the Exhibition Industry (2007): The World Map of Exhibition Venues and Future Trends. October, Paris: UFI.

Wang, F.-H. and Guo, J.-R. (2012): Blue Book of Convention \& Exhibition Economy. Annual Report on China's Convention \& Exhibition Economy 2012. Beijing: Social Sciences Academic Press (in Chinese).

Wang, J. H. and Lee, C. K. (2007): Global production networks and local institution building: The development of the information-technology industry in Suzhou, China. Environment and Planning A 39: 1873-1888.

Wang, C. C., Lin, G. C. S. and Li, G. (2010): Industrial clustering and technological innovation in China: New evidence from the ICT industry in Shenzhen. Environment and Planning A 42: 1987-2010.

Wei, Y. H. D., Zhou, Y., Sun, Y. F. and Lin, G. C. S. (2012): Production and R\&D networks of foreign ventures in China: Implications for technological dynamism and regional development. Applied Geography 32: 106-118.

Weller, S. (2008): Beyond "global production networks": Australian Fashion Week's transsectoral synergies. Growth and Change 39: 104-122.

Wenger, E. (1998): Communities of Practice: Learning, Meaning, and Identity. Cambridge: Cambridge University Press.

Yeung H.W.-C. (2009): Regional development and the competitive dynamics of global production networks: An East Asian perspective. Regional Studies 43 325-351.

Young, R. (2004): Plastics in China: Exhibitors mostly tout existing products. Plastics News 16 (24), 14-15. 
Table 1: Development of Convention Centers in China by Location (City) and Size (Indoor Exhibition Space $\left.\geq 50,000 \mathrm{~m}^{2}\right), 2009-2011$

(Sources: Wang and Guo 2010; Guo 2011; 2012)

\begin{tabular}{|c|c|c|c|c|c|c|}
\hline \multirow[t]{2}{*}{ City (Province) } & \multicolumn{3}{|c|}{$\begin{array}{l}\text { Number of convention } \\
\text { centers }\end{array}$} & \multicolumn{3}{|c|}{ Total indoor exhibition space $\left(\mathrm{m}^{2}\right)$} \\
\hline & 2009 & 2010 & 2011 & 2009 & 2010 & 2011 \\
\hline Beijing* & 3 & 2 & 2 & 236,600 & 173,000 & 173,000 \\
\hline Chengdu (Sichuan) & 1 & 2 & 2 & 55,000 & 165,000 & 143,000 \\
\hline Dalian (Liaoning)* & 1 & - & - & 79,300 & - & - \\
\hline Dongguan (Guangdong) & 1 & 1 & 1 & 100,000 & 100,000 & 100,000 \\
\hline Fuzhou/ Fujian & - & 1 & 1 & - & 80,000 & 80,000 \\
\hline Guangzhou/ Guangdong & 5 & 5 & 5 & 474,600 & 684,400 & 684,400 \\
\hline Guiyang/ Guizhou & - & 1 & 1 & - & 54,000 & 54,000 \\
\hline Hangzhou/Zhejiang & 2 & 2 & 2 & 121,000 & 121,000 & 121,000 \\
\hline Harbin/ Heilongjiang & - & 1 & 1 & - & 56,500 & 56,500 \\
\hline Hefei/ Anhui & - & 1 & 1 & - & 120,000 & 120,000 \\
\hline $\begin{array}{l}\text { Hohhot/ Inner } \\
\text { Mongolia* }\end{array}$ & 1 & - & - & 57,000 & - & - \\
\hline Jinan/ Shandong* & 2 & - & - & 190,000 & - & - \\
\hline Jinhua/ Zhejiang & 1 & 2 & 2 & 100,000 & 193,200 & 193,200 \\
\hline Kunming/ Yunnan* & 1 & - & - & 70,000 & - & - \\
\hline Nanchang/ Jiangxi* & 1 & - & - & 75,000 & - & - \\
\hline Nanjing/ Jiangsu & 1 & 1 & 1 & 72,000 & 110,000 & 110,000 \\
\hline Nanning/ Guangxi & 1 & 1 & 1 & 80,000 & 65,800 & 65,800 \\
\hline Ningbo/ Zhejiang & 1 & 1 & 1 & 51,000 & 51,000 & 51,000 \\
\hline Qingdao/ Shandong & - & 1 & 2 & - & 59,000 & 179,000 \\
\hline
\end{tabular}




\begin{tabular}{l|ccc|ccc} 
Shanghai & 1 & 3 & 3 & 126,500 & 271,800 & 345,500 \\
Shenyang/ Liaoning & - & 1 & 1 & - & 105,200 & 105,200 \\
Shenzhen/ Guangdong & 1 & 1 & 1 & 105,000 & 105,000 & 105,000 \\
Shijiazhuang/ Heibei & - & 1 & 1 & - & 100,000 & 60,000 \\
Suzhou/ Jiangsu & - & 2 & 2 & - & 131,000 & 131,000 \\
Taizhou/ Zhejiang* & 1 & - & - & 65,100 & - & - \\
Tianjin & - & - & 1 & - & - & 56,200 \\
Weifang/ Shandong* & 2 & 1 & 1 & 121,800 & 70,000 & 70,000 \\
Weihai/ Shandong* & 1 & - & - & 80,000 & - & - \\
Wuhan/ Hubei & - & - & 1 & - & - & 150,000 \\
Xiamen/ Fujian & 1 & 1 & 1 & 80,000 & 60,000 & 60,000 \\
Xian/ Shaanxi & - & 1 & 1 & - & 66,000 & 66,000 \\
Xianyang/ Shaanxi* & 1 & - & - & 66,000 & - & - \\
Zhengzhou/ Henan & 1 & 1 & 1 & 65,000 & 74,000 & 74,000 \\
Zibo/ Shandong & - & 1 & 1 & - & 60,800 & 60,800 \\
\hline Total & 31 & 35 & 38 & $2,470,900$ & $3,076,700$ & $3,414,600$ \\
\hline
\end{tabular}

Note: * Between 2009 and 2011, the number of convention centers decreased in cities, such as Beijing, Dalian, Hohhot, Jinan, Kunming, Nanchang, Taizhou, Weifang, Weihai and Xianyang, as some facilities were restructured for different uses. 
Table 2: Number of Exhibitors and Visitors by Origin and Exhibition Space at Selected Chinese Trade Fairs, 2010

(Sources: China International Exhibition on Gases Technology, Equipment and Application 2010, China International Industry Fair 2011, Information \& Communication Technology Show 2010a, 2010b, Metalworking and CNC Machine Tool Show 2011)

\begin{tabular}{|c|c|c|c|c|}
\hline Trade fair indicator & $\begin{array}{c}\text { CIIF, } \\
\text { Shanghai }\end{array}$ & $\begin{array}{l}\text { MWCS, } \\
\text { Shanghai }\end{array}$ & $\begin{array}{c}\text { ICTS, } \\
\text { Shanghai }\end{array}$ & $\begin{array}{l}\text { IG China, } \\
\text { Chengdu }\end{array}$ \\
\hline Exhibition space & $103,500 \mathrm{~m}^{2}$ & $34,500 \mathrm{~m}^{2}$ & $11,500 \mathrm{~m}^{2}$ & $12,000 \mathrm{~m}^{2}$ \\
\hline Exhibitors & 1,653 & 384 & 188 & 220 \\
\hline Overseas exhibitors & $34 \%$ & $35 \%$ & $16 \%$ & $9 \%$ \\
\hline Important countries of & Japan, & n.a. & n.a. & Germany, USA, \\
\hline origin of overseas & Germany, & & & Russia \\
\hline exhibitors & Taiwan, USA & & & \\
\hline Visitors & 116,800 & n.a. & n.a. & 10,000 \\
\hline Overseas visitors & Few & Few & Negligible & $3 \%$ \\
\hline \multicolumn{5}{|c|}{ Notes: $\mathrm{CIIF}=$ China International Industry Fair; MWCS = Metalworking and CNC Machine } \\
\hline \multicolumn{5}{|c|}{ Tool Show; ICTS = Information \& Communication Technology Show; IG China = China } \\
\hline International Exhibitio & on Gases Techn & gy, Equipme & d Applicatio & a. $=$ not \\
\hline
\end{tabular}


Table 3: Interview Statistics at Selected Chinese Trade Fairs, 2010

\begin{tabular}{lcccc}
\hline Trade fair & \multicolumn{2}{c}{ Interviews conducted } & \multicolumn{2}{c}{ Rejections } \\
& Number & Share & Number & Response rate \\
\hline MWCS, Shanghai & 45 & $44 \%$ & 4 & $92 \%$ \\
ICTS, Shanghai & 24 & $24 \%$ & 7 & $77 \%$ \\
IG China, Chengdu & 33 & $32 \%$ & 2 & $94 \%$ \\
\hline Total & 102 & $100 \%$ & 13 & $89 \%$ \\
\hline
\end{tabular}

Notes: $\mathrm{MWCS}=$ Metalworking and CNC Machine Tool Show; ICTS = Information \& Communication Technology Show; IG China = China International Exhibition on Gases Technology, Equipment and Application.

Table 4: Firms Interviewed at Selected Chinese Trade Fairs by Country of Origin, 2010

\begin{tabular}{lcccccc}
\hline Country of & \multicolumn{2}{c}{ MWCS, Shanghai } & \multicolumn{2}{c}{ ICTS, Shanghai } & \multicolumn{2}{c}{ IG China, Chengdu } \\
origin & Number & Share & Number & Share & Number & Share \\
\hline China & 23 & $53 \%$ & 15 & $68 \%$ & 21 & $68 \%$ \\
Asia-Pacific & 10 & $23 \%$ & 4 & $18 \%$ & 2 & $6 \%$ \\
USA & 1 & $2 \%$ & 2 & $9 \%$ & 4 & $13 \%$ \\
Other country & 9 & $21 \%$ & 1 & $5 \%$ & 4 & $13 \%$ \\
\hline Total & 43 & $99 \%$ & 22 & $100 \%$ & 31 & $100 \%$ \\
\hline
\end{tabular}

Notes: MWCS = Metalworking and CNC Machine Tool Show; ICTS = Information \& Communication Technology Show; IG China = China International Exhibition on Gases Technology, Equipment and Application. 
Table 5: Firms Interviewed at Selected Chinese Trade Fairs by Ownership Status, 2010

\begin{tabular}{lcccccc}
\hline Ownership & \multicolumn{2}{c}{ MWCS, Shanghai } & \multicolumn{2}{c}{ ICTS, Shanghai } & \multicolumn{2}{c}{ IG China, Chengdu } \\
status & Number & Share & Number & Share & Number & Share \\
\hline $\begin{array}{l}\text { Privately owned } \\
\text { (Chinese) }\end{array}$ & 18 & $42 \%$ & 8 & $36 \%$ & 15 & $50 \%$ \\
$\begin{array}{l}\text { State-owned or } \\
\text { state holding }\end{array}$ & 5 & $11 \%$ & 4 & $14 \%$ & 5 & $26 \%$ \\
$\begin{array}{l}\text { (Chinese) } \\
\text { Foreign-owned }\end{array}$ & 18 & $42 \%$ & 6 & $27 \%$ & 10 & $33 \%$ \\
Foreign-Chinese & 2 & $5 \%$ & 4 & $18 \%$ & 0 & $0 \%$ \\
joint venture & & & & & & \\
\hline Total & 43 & $100 \%$ & 22 & $100 \%$ & 30 & $99 \%$ \\
\hline
\end{tabular}

Notes: MWCS = Metalworking and CNC Machine Tool Show; ICTS = Information \& Communication Technology Show; IG China = China International Exhibition on Gases Technology, Equipment and Application. 
Table 6: Firms Interviewed at Selected Chinese Trade Fairs by Age, 2010

\begin{tabular}{lcccccc}
\hline Year & \multicolumn{2}{c}{ MWCS, Shanghai } & \multicolumn{2}{c}{ ICTS, Shanghai } & \multicolumn{2}{c}{ IG China, Chengdu } \\
established & Number & Share & Number & Share & Number & Share \\
\hline $2000-2009$ & 14 & $34 \%$ & 9 & $41 \%$ & 11 & $42 \%$ \\
$1990-1999$ & 13 & $32 \%$ & 8 & $36 \%$ & 6 & $23 \%$ \\
$1980-1989$ & 2 & $5 \%$ & 4 & $18 \%$ & 2 & $8 \%$ \\
$1970-1979$ & 3 & $7 \%$ & 0 & $0 \%$ & 1 & $4 \%$ \\
$1900-1969$ & 9 & $22 \%$ & 1 & $5 \%$ & 1 & $4 \%$ \\
Before 1900 & 0 & $0 \%$ & 0 & $0 \%$ & 5 & $19 \%$ \\
\hline Total & 41 & $100 \%$ & 22 & $100 \%$ & 26 & $100 \%$ \\
\hline
\end{tabular}

Notes: MWCS $=$ Metalworking and CNC Machine Tool Show; ICTS $=$ Information $\&$ Communication Technology Show; IG China = China International Exhibition on Gases Technology, Equipment and Application. 
Table 7: Firms Interviewed at Selected Chinese Trade Fairs by Size, 2010

\begin{tabular}{|c|c|c|c|c|c|c|}
\hline \multirow{2}{*}{$\begin{array}{l}\text { Number of } \\
\text { employees }\end{array}$} & \multicolumn{2}{|c|}{ MWCS, Shanghai } & \multicolumn{2}{|c|}{ ICTS, Shanghai } & \multicolumn{2}{|c|}{ IG China, Chengdu } \\
\hline & Number & Share & Number & Share & Number & Share \\
\hline Less than 100 & 13 & $32 \%$ & 6 & $27 \%$ & 9 & $39 \%$ \\
\hline $100-499$ & 17 & $41 \%$ & 7 & $32 \%$ & 9 & $39 \%$ \\
\hline $500-999$ & 2 & $5 \%$ & 4 & $18 \%$ & 0 & $0 \%$ \\
\hline 1000 and more & 9 & $22 \%$ & 5 & $23 \%$ & 5 & $22 \%$ \\
\hline Total & 41 & $100 \%$ & 22 & $100 \%$ & 23 & $100 \%$ \\
\hline
\end{tabular}

Notes: MWCS $=$ Metalworking and CNC Machine Tool Show; ICTS $=$ Information $\&$ Communication Technology Show; IG China = China International Exhibition on Gases Technology, Equipment and Application. 